\title{
Synthesis of Novel Quinolines using TsOH/Ionic Liquid under Microwave
}

\author{
Liziê D. T. Prola, Lilian Buriol, Clarissa P. Frizzo, Guilherme S. Caleffi, Mara R. B. Marzari, \\ Dayse N. Moreira, Helio G. Bonacorso, Nilo Zanatta and Marcos A. P. Martins*
}

\author{
Núcleo de Química de Heterociclos (NUQUIMHE), Departamento de Química, \\ Universidade Federal de Santa Maria (UFSM), 97105-900 Santa Maria-RS, Brazil
}

Neste trabalho, 3-haloacetil-4-metilquinolinas foram sintetizadas a partir da reação de 4-alcóxi-3-alquen-2-onas $\left[\mathrm{R}^{1} \mathrm{C}(\mathrm{O}) \mathrm{CH}=\mathrm{C}\left(\mathrm{R}^{2}\right) \mathrm{OCH}_{3}\right.$, onde $\mathrm{R}^{1}=\mathrm{CF}_{3}, \mathrm{CCl}_{3}, \mathrm{CHCl}_{2}, \mathrm{CF}_{2} \mathrm{Cl}$ e $\mathrm{CF}_{2} \mathrm{CF}_{3}$ e $\mathrm{R}^{2}=\mathrm{Me}, \mathrm{Et}, \mathrm{Pr}, \mathrm{Bu}, i$-Bu e $i$-Pe] e 2-aminoacetofenona. A reação foi realizada em líquido iônico e ácido 4-toluenosolfônico sob irradiação de micro-ondas. Os resultados mostraram que o método catalítico foi efetivo e os produtos foram formados em tempos de reação curtos (10-20 min) e com bons rendimentos $(70-91 \%)$.

In this work, 3-haloacetyl-4-methylquinolines were synthesized from the reaction of 4-alkoxy3-alken-2-ones $\left[\mathrm{R}^{1} \mathrm{C}(\mathrm{O}) \mathrm{CH}=\mathrm{C}\left(\mathrm{R}^{2}\right) \mathrm{OCH}_{3}\right.$, where $\mathrm{R}^{1}=\mathrm{CF}_{3}, \mathrm{CCl}_{3}, \mathrm{CHCl}_{2}, \mathrm{CF}_{2} \mathrm{Cl}_{1} \mathrm{CF}_{2} \mathrm{CF}_{3}$ and $\mathrm{R}^{2}=\mathrm{Me}$, Et, $\mathrm{Pr}, \mathrm{Bu}, i$-Bu and $i$-Pe] and 2-aminoacetophenone. The reaction was performed in ionic liquid and 4-toluene sulfonic acid under microwave irradiation. Results showed that the catalytic method was effective. Products were formed in a short time (10-20 min) and presented good yields $(70-91 \%)$.

Keywords: ionic liquid, quinoline, toluene sulfonic acid, microwave-assisted synthesis (MW), enones

\section{Introduction}

Quinolines are very important heterocyclic compounds since they display interesting physiological and pharmacological activities. The quinoline moiety is present as a substructure in a broad range of pharmacologically active compounds, most notably in anti-malaria agents. ${ }^{1}$ This nucleus has also played a historical role in organic chemistry as a target for structural determination and total synthesis. ${ }^{2-5}$

The most described synthetic route to quinolines is known as Friedländer annulations. ${ }^{6,7}$ In this reaction, substituted anilines or 2-carbonyl-substituted anilines (C-C-C-N unit) react with carbonyl compounds containing a reactive $\alpha$-methylene group (C-C unity). Generally, the reactive $\alpha$-methylene group is part of unsymmetrical ketones, ${ }^{8} 1,3$-dicarbonyl compounds ${ }^{9}$ or $\beta$-ketoesters. ${ }^{10-12}$ Quinolines from these precursors present a 3-acyl group such as acetyl, benzoyl, thienyl, furyl, carboxylate and trifluoroacetyl. ${ }^{9}$ However, quinolines with electron-withdrawing groups such as perfluoroalkyl,

*e-mail: mmartins@base.ufsm.br trichloromethyl and dichloromethyl groups attached at 3-position cannot be obtained from unsymmetrical ketones, ${ }^{8} 1,3$-dicarbonyl compounds ${ }^{9}$ or $\beta$-ketoesters due to the difficulty to obtain the precursors.

Our research group has developed a general procedure to prepare 4-alkoxyvinyl ketones and has exhaustively studied the versatility of these precursors in heterocyclic synthesis. ${ }^{13-20}$ In 2008 , our group described the synthesis of a set of trifluoromethyl-cycloalka[ $b$ ]quinolines from reactions of mono-substituted anilines and 2-trifluoroacetyl1-methoxycycloalkenes using poly-phosphoric acid (PPA). ${ }^{21}$ In this synthesis, it was explored the well-known reactivity of 1,3-dielectrophilic of 4-alkoxyvinyl ketones. In the present work, continuing our studies on the reactivity of 4-alkoxyvinyl ketones in heterocyclic synthesis, we proposed a novel route for the synthesis of quinolines. We believe that the reaction of 4-alkoxyvinylhalomethyl ketone precursors with 2-carbonyl-substituted anilines can furnish quinolines with perfluoroalkyl, trichloromethyl and dichloromethyl groups attached at 3-position. For this reaction route to work, 4-alkoxyvinylhalomethyl ketones should react at the electrophilic center (at carbonyl) and in the nucleophilic site $(\mathrm{C} \alpha \mathrm{C}=\mathrm{O})$. 
In addition, unconventional activation techniques such as microwave $\mathrm{e}^{22,23}$ and ultrasound $\mathrm{d}^{24}$ have also been used in organic reactions as a way of reducing reaction times, and of increasing product yields when compared to conventional methods. ${ }^{25} \mathrm{~A}$ recent trend in this area is microwave-assisted synthesis using ionic liquids (ILs) as solvent, co-solvent, catalyst, and/or template. ${ }^{26}$ Due to their ionic nature, ILs allow highly effective interactions with microwave (MW) energy for the rapid generation of products with high yields. ${ }^{27}$ Thus, here it is also investigated the synthesis of quinolines from 4-alkoxyvinylhalomethyl ketones in the presence of $1 H$-methylimidazolium toluene sulfonate [HMIM][TsO] as a Brønsted acidic ionic liquid and under microwave irradiation since our previous works have shown that $\mathrm{ILs}^{15,16}$ and/or ILs/microwave (MW) ${ }^{17}$ are efficient in heterocyclic synthesis.

\section{Experimental}

\section{General}

Unless otherwise indicated, all common reagents and solvents were used as obtained from commercial suppliers without further purification. ${ }^{1} \mathrm{H}$ NMR (nuclear magnetic resonance) spectra were recorded on a Bruker DPX-200 $\left({ }^{1} \mathrm{H}\right.$ at $\left.200 \mathrm{MHz}\right)$ and ${ }^{13} \mathrm{C}$ NMR on a Bruker DPX $400\left({ }^{1} \mathrm{H}\right.$ at $400.13 \mathrm{MHz}$ and ${ }^{13} \mathrm{C}$ at $100.62 \mathrm{MHz}$ ) in $5 \mathrm{~mm}$ tubes, in $\mathrm{CDCl}_{3}$ /TMS solutions at $298 \mathrm{~K}$. The general reproducibility of chemical shift data was estimated to be better than $\pm 0.01 \mathrm{ppm}$. All spectra were acquired in a $5 \mathrm{~mm}$ tube, at natural abundance. $J$ values are given in Hz. Mass spectra (MS) were registered in a HP 5973 MSD connected to an HP 6890 GC and interfaced by a Pentium PC. The gas chromatographer (GC) was equipped with a split-splitless injector, cross-linked to a HP-5 capillary column (30 m, $0.32 \mathrm{~mm}$ of internal diameter), and helium was used as the carrier gas. The melting points (mp) were measured using a Microquímica MQAPF 301 Model. Experiments were performed in a Discover CEM MW using the simultaneous cooling mode of operation. X-ray diffraction measurements were carried out by graphite monochromatized Mo $\mathrm{K}_{\alpha}$ radiation with $\mathrm{k}=0.71073 \AA$ on a Bruker SMART CCD diffractometer. ${ }^{28}$ Structures were solved with direct methods using the SHELXS-97 program and refined on $F^{2}$ by full-matrix least-squares using SHELXL97. ${ }^{29}$ The absorption correction was performed by Gaussian methods. ${ }^{30}$ Figure 1 depicts the ORTEP view, ${ }^{31}$ a diagram of the molecule indicating the atom numbering scheme with thermal ellipsoids at $30 \%$ probability. Aminoacetophenone was commercially available. 4-Alkoxy-3-alken-2-ones were obtained from the acylation reaction of enol ether or acetal with respective acylant, in accordance with the methodology developed in our laboratory. ${ }^{20}$ The ionic liquid [HMIM][TsO] was prepared according to procedures from the literature. ${ }^{32}$

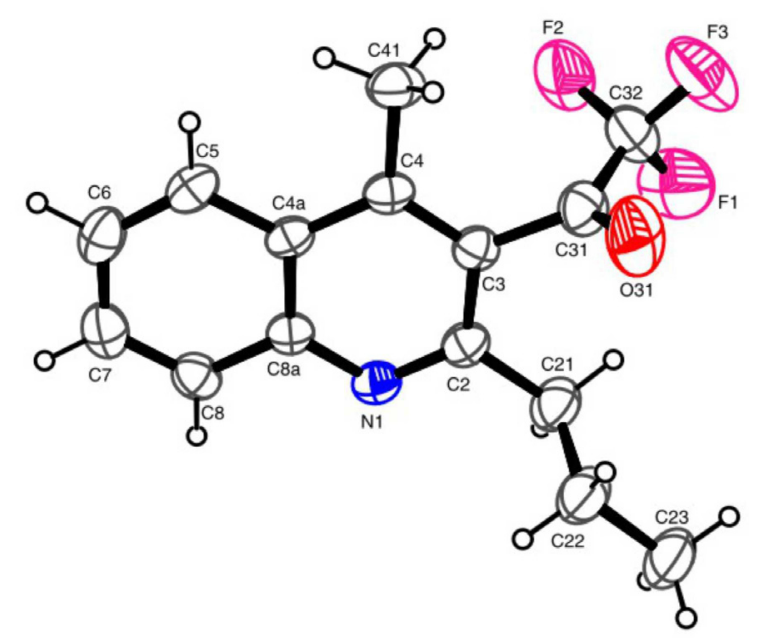

Figure 1. ORTEP ${ }^{31}$ of the 3-trifluoroacetyl-4-methyl-2-propyl-quinoline (3c) with thermal ellipsoids drawn at $30 \%$ probability level.

Typical procedure for the synthesis of quinolines in MW

A $10 \mathrm{~mL}$ microwave vessel equipped with a standard cap (vessel commercially furnished by CEM Discover) was filled with 4-alkoxyvinyl ketone (1.2 mmol for products 3a-f, 8a, 10a, 11a, and $1.0 \mathrm{mmol}$ for 9a), 2-aminoacetophenone $(1.0 \mathrm{mmol})$, [HMIM][TsO] $(1.0 \mathrm{mmol})$ and $\mathrm{TsOH}$ $(1.0 \mathrm{mmol})$. After the vessel was sealed, the sample was irradiated at $150{ }^{\circ} \mathrm{C}$ for $\mathbf{3 a - f}, \mathbf{1 0 a}, \mathbf{1 1 a}, 90{ }^{\circ} \mathrm{C}$ for $\mathbf{8 a}$ and $80^{\circ} \mathrm{C}$ for $\mathbf{9 a}$ for the time indicated in Scheme 1. Reaction conditions were plotted in Synergies version 3.5.9 software, applying the power of $200 \mathrm{~W}$ as the maximum level of irradiation and a maximum level of internal vessel pressure of $250 \mathrm{psi}$. The irradiation power was in the range of $4-10 \mathrm{~W}$ for reactions at $150{ }^{\circ} \mathrm{C}$, without simultaneous cooling, $10-13 \mathrm{~W}$ for reactions at $90^{\circ} \mathrm{C}$, and $15-51 \mathrm{~W}$ for reactions at $80^{\circ} \mathrm{C}$ with simultaneous cooling. The reaction mixture was subsequently cooled to $50^{\circ} \mathrm{C}$ by compressed air. The reaction mixture was isolated with chloroform $(5 \mathrm{~mL})$ and washed with water $(3 \times 5 \mathrm{~mL})$. The chloroform was evaporated under vacuum (reduced pressure) and the products were obtained in a pure form without further purification. The structure of the compounds was confirmed by ${ }^{1} \mathrm{H} /{ }^{13} \mathrm{C}$ NMR spectroscopy, mass spectrometry and elemental analysis.

Procedure for the synthesis of quinolone $\mathbf{3 a}$ in conventional thermal heating

4-Alkoxyvinyl ketone $\mathbf{1}$ (1.2 $\mathrm{mmol})$, acetophenone $\mathbf{2}$ (1.0 mmol), [HMIM][TsO] $(1.0 \mathrm{mmol})$ and $\mathrm{TsOH}$ 


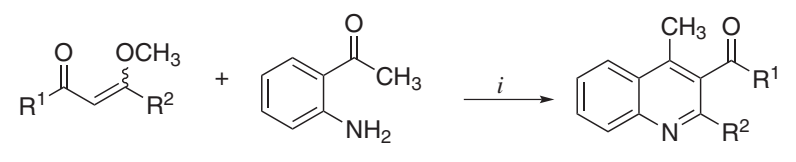

1a-f, 4a, 5a, 6a, 7a 2 3a-f, 8a, 9a, 10a, 11a

\begin{tabular}{|c|c|c|c|c|c|c|}
\hline Reactant & $\mathrm{R}^{1}$ & $\mathrm{R}^{2}$ & $\begin{array}{c}\text { time / } \\
\text { min }\end{array}$ & $\begin{array}{c}\text { Temperature } \\
/{ }^{\circ} \mathrm{C}\end{array}$ & Product & $\begin{array}{c}\text { Yield }^{\mathrm{a}} / \\
\%\end{array}$ \\
\hline $1 \mathrm{a}$ & $\mathrm{CF}_{3}$ & $\mathrm{Me}$ & 10 & 150 & $3 a$ & 87 \\
\hline $1 b$ & $\mathrm{CF}_{3}$ & Et & 10 & 150 & $3 b$ & 70 \\
\hline $1 c$ & $\mathrm{CF}_{3}$ & $\operatorname{Pr}$ & 10 & 150 & $3 c$ & 72 \\
\hline 1d & $\mathrm{CF}_{3}$ & $\mathrm{Bu}$ & 20 & 150 & $3 d$ & 70 \\
\hline 1e & $\mathrm{CF}_{3}$ & ${ }^{i} \mathrm{Pe}$ & 20 & 150 & $3 e$ & 74 \\
\hline 1f & $\mathrm{CF}_{3}$ & ${ }^{i} \mathrm{Bu}$ & 20 & 150 & $3 f$ & 75 \\
\hline $4 a$ & $\mathrm{CCl}_{3}$ & $\mathrm{Me}$ & 10 & 90 & $8 a$ & 91 \\
\hline $5 a$ & $\mathrm{CHCl}_{2}$ & $\mathrm{Me}$ & 10 & 80 & $9 a$ & 83 \\
\hline $6 a$ & $\mathrm{CF}_{2} \mathrm{Cl}$ & $\mathrm{Me}$ & 10 & 150 & $10 \mathrm{a}$ & 75 \\
\hline $7 \mathbf{a}$ & $\mathrm{CF}_{2} \mathrm{CF}_{3}$ & $\mathrm{Me}$ & 10 & 150 & 11a & 82 \\
\hline
\end{tabular}

${ }^{\mathrm{a}}$ Yield of isolated product.

Scheme 1. Reaction conditions and yields of quinolines series

$(1.0 \mathrm{mmol})$ were placed into a round-bottom flask equipped with a stir bar. The mixture was stirred for 10, 20, 60 and $120 \mathrm{~min}$ at $150^{\circ} \mathrm{C}$. Products were isolated with chloroform $(5 \mathrm{~mL})$ and washed with water $(3 \times 5 \mathrm{~mL})$. The chloroform was evaporated under vacuum (reduced pressure) and products were obtained in a pure form without further purification.

\section{Results and Discussion}

To understand the influence of different variables in this reaction, several components were studied to optimize our procedure. Firstly, it was carried out the reaction using 4-alkoxyvinyl ketones $\mathbf{1}$ and 2-aminoacetophenone $\mathbf{2}$ to obtain the quinoline 3 under microwave irradiation in $20 \mathrm{~min}$ (Table 1). In a first set of experiments, it was studied the influence of different reaction media, using $\mathrm{HCl}$ as catalyst. The desired product was obtained in moderate yields for all the media, where $[\mathrm{HMIM}][\mathrm{TsO}]$ and $[\mathrm{BMIM}]\left[\mathrm{BF}_{4}\right]$ were the best for this reaction (Table 1, entry 5). In order to increase the yields, it was evaluated the use of 4-toluenesulfonic acid $(\mathrm{TsOH})$ as catalyst. The efficiency of the IL-acid combination to promote the reaction was examined (Table 1). It was found that variation of the acid had an effective influence. While hydrochloric acid afforded the desired product in moderate yields (entries 1, 3 and 5) or did not result in the complete conversion of the reagent into the product (entry 3), $\mathrm{TsOH}$ promoted the total conversion of reactants and afforded good yields in ionic liquids (entry 4 and 6) and moderate yields in ethanol (entry 2). With these results, $\mathrm{TsOH}$ was selected as the best catalyst.

Table1. Different reaction media for the reaction between $\mathbf{1}$ and $\mathbf{2}$<smiles>COC(C)=CC(=O)C(F)(F)F</smiles>

\begin{tabular}{|c|c|c|c|}
\hline entry & $\begin{array}{l}\text { id, reaction media } \\
\text { Reaction media }\end{array}$ & $\begin{array}{l}{ }^{\circ} \mathrm{C}, 201 \\
\text { Acid }^{\mathrm{a}, \mathrm{b}} \\
\end{array}$ & $\begin{array}{l}\mathrm{N} \\
\text { Yield }^{\mathrm{c}} / \% \\
\end{array}$ \\
\hline 1 & $\mathrm{EtOH}$ & $\mathrm{HCl}$ & 44 \\
\hline 2 & $\mathrm{EtOH}$ & $\mathrm{TsOH}$ & 59 \\
\hline 3 & {$[\mathrm{BMIM}]\left[\mathrm{BF}_{4}\right]$} & $\mathrm{HCl}$ & $71^{\mathrm{d}}$ \\
\hline 4 & $\left.[\mathrm{BMIM}] \mathrm{BF}_{4}\right]$ & $\mathrm{TsOH}$ & 80 \\
\hline 5 & {$[\mathrm{HMIM}][\mathrm{TsO}]$} & $\mathrm{HCl}$ & 64 \\
\hline 6 & {$[\mathrm{HMIM}][\mathrm{TsO}]$} & $\mathrm{TsOH}$ & 79 \\
\hline
\end{tabular}

Reaction time was also analyzed. The reaction time using [BMIM] $\left[\mathrm{BF}_{4}\right]$ was reduced to $10 \mathrm{~min}$, resulting in a mixture containing the product and $3 \%$ of $\mathbf{2}$. This indicates the incomplete conversion of reactants into products. Therefore, the variation of the reaction time was studied using ionic liquid [HMIM][TsO] (Table 2), in which the best yield was obtained in $10 \mathrm{~min}$, with a reduction in yield at shorter (5 $\mathrm{min})$ and longer (20 $\mathrm{min}$ ) reaction times (Table 2).

Table 2. Reaction time for the reaction between $\mathbf{1}$ and $\mathbf{2}$ in ionic liquid [HMIM][TsO]<smiles>COC(C)=CC(=O)C(F)(F)F</smiles>

1

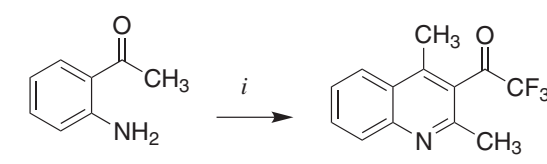

2

3 $i$ : TsOH, [HMIM] [TsO], $150^{\circ} \mathrm{C}, \mathrm{MW}$

\begin{tabular}{lcc}
\hline entry & time / min & Yield $^{\mathrm{a}} \%$ \\
\hline 1 & 20 & 79 \\
2 & 10 & 86 \\
3 & 5 & 60 \\
\hline
\end{tabular}

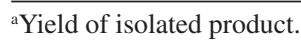

In order to gain insight into the generality of this reaction, a catalytic cyclocondensation reaction was performed on several other 4-alkoxyvinyl ketones using the established reaction conditions. Thus, other quinolines were prepared, varying the substituent at 2- and 3-positions of the quinolinic ring. 4-Alkoxyvinyl ketones 1a-f, 4a, 5a, 6a and 7a (Scheme 1) were obtained from the acylation reaction of enol ether or acetal with trifluoroacetic anhydride (1a-f), trichloroacetyl chloride (4a), dichloroacetyl chloride (5a), chlorodifluoroacetic anhydride (6a) and perfluoropropionic anhydride (7a), respectively, in accordance with the 
methodology developed in our laboratory. ${ }^{13-20}$ Different 4-alkyl- and 4-aryl-4-alkoxyvinyl ketones were used in the reaction. While 4-aryl-4-methoxy-3-alken-2-ones were not completely converted into quinolines $\mathbf{3}$, reactions with 4-alkyl-4-alkoxyvinyl ketones resulted in total conversion into products in good yields (Scheme 1). Therefore, it was decided to change the substituent at the 1-position of 4-alkoxyvinyl ketones to obtain new quinolines in good yields (Scheme 1). Quinolines were isolated from extraction with chloroform and washed with water. The ionic liquid was recovered by the evaporation of water and successive washing with dichloromethane. After the evaporation of the solvent, the ionic liquid was reused without any loss of activity. The isolated yields of products 3a-f, 8-11a are summarized in Scheme 1.

To show the importance of MW to promote quinoline synthesis, the reaction of 4-alkoxyvinyl ketone $\mathbf{1}$ (1.2 equiv) and 2 -aminoacetophenone (1 equiv) 2 was carried out under conventional thermal heating using [HMIM][TsO]. Times and temperatures previously established were used (Table 2). It was found that at $10 \mathrm{~min}$, the yield of the product was lower (59\%) than that obtained in MW (86\%). Subsequently, the reaction time was increased to $20 \mathrm{~min}$ and the yield was very similar to that obtained in $10 \mathrm{~min}(60 \%)$. Only after $60 \mathrm{~min}(83 \%)$ and $120 \mathrm{~min}(85 \%)$ under conventional thermal heating, the product was obtained in yields similar to those obtained in MW.

In accordance with Martínez-Palou, ${ }^{27}$ the synergic effects of ionic liquid and MW in promoting this reaction are due to the ionic and polar nature of ILs, which allow for highly effective interactions with microwave (MW) energy, generating products in short times and with high yields.

Products were characterized by ${ }^{1} \mathrm{H},{ }^{13} \mathrm{C}$ NMR spectroscopy, mass spectrometry and melting points for solid products. Quinolines 3a-f, 8a-11a showed a set of ${ }^{1} \mathrm{H}$ and ${ }^{13} \mathrm{C}$ NMR data that corresponded to the proposed structures. Compounds 3a-f, 9a, 10a and 11b showed ${ }^{1} \mathrm{H}$ NMR chemical shifts of the methyl protons $\left(\mathrm{CH}_{3} \mathrm{H} 9\right)$ as a singlet at $\delta 2.61$, and compound $\mathbf{8 a}$ showed a shift of the methyl protons $\left(\mathrm{CH}_{3}, \mathrm{H} 9\right)$ as singlet at $\delta 2.81$. The same compounds presented ${ }^{13} \mathrm{C}$ NMR spectra with chemical shifts typical of quinoline rings in the ranges of $\delta$ 152.6-157.8 (C-2), 142.7-143.5 (C-3) and 146.2-147.9 (C-4).

Although the features of the Friedländer reaction are generally well understood, its mechanism has not been clearly established. Experimental reports support two different mechanistic proposals. Starting from 2-carbonylsubstituted aniline and the carbonyl partner, one pathway involves the initial formation of the Schiff base followed by an intramolecular aldol reaction to give the hydroxy imine, followed by loss of water to produce the quinoline. Alternatively, it has been proposed that the initial ratelimiting step is an intermolecular aldol reaction furnishing the quinoline. ${ }^{7}$ However, regarding the substrate, it has been studying here, another mechanism seems to be operating, where the reaction is likely to occur by the initial formation of an enamino intermediate (IIa-IIb). This can be evidenced by the fact that during the optimization steps of reaction, it was occasionally isolated the enamino ketone intermediate. Therefore, the reaction involved an initial $\mathrm{C}-\mathrm{N}$ bond formation, from the attack of the nitrogen atom of the $\mathrm{NH}_{2}$ group on the $\beta$-carbon of the 4-alkoxyvinyl ketones $\mathbf{1}$ with subsequent substitution of the alkoxy group to furnish the enamino ketone intermediate (IIa-IIb). In a second moment, there was an intramolecular nucleophilic addition of the $\alpha$-carbon to the carbonyl group of the 2-aminoacetophenone with subsequent elimination of one molecule of water (III) (Scheme 2). ${ }^{33}$ We suggest that the

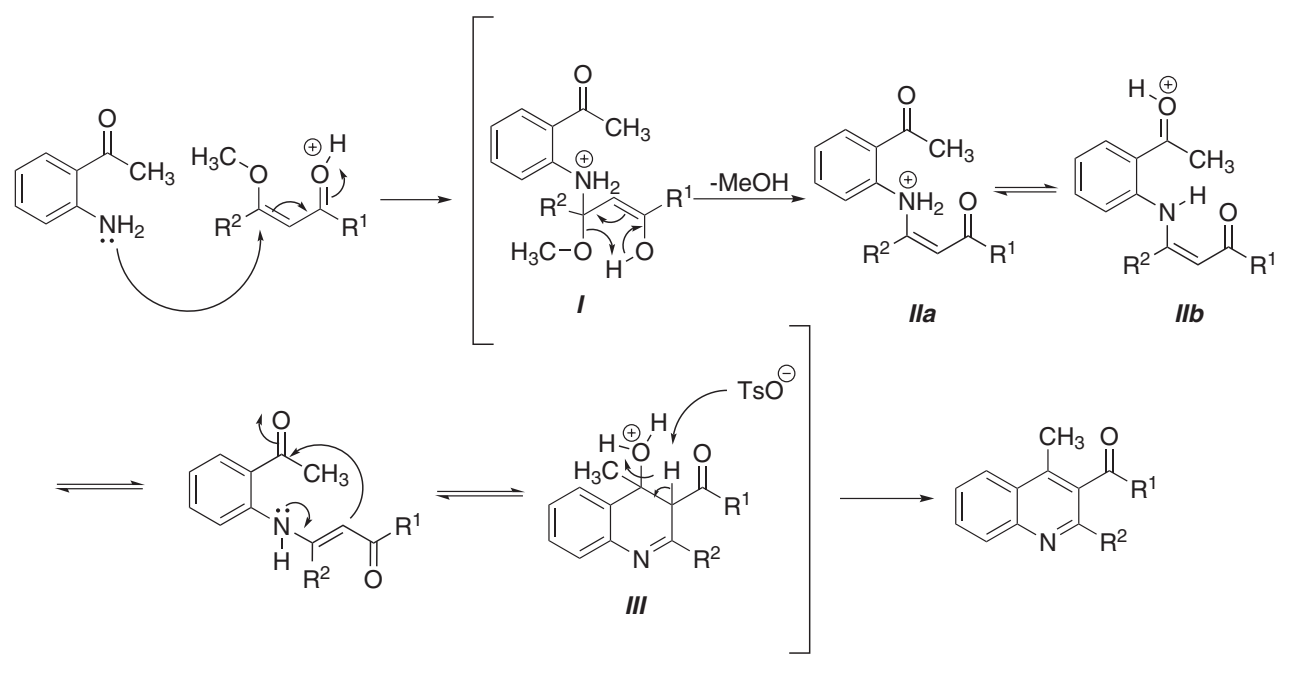

Scheme 2. Mechanism proposed to reaction of 4-alkoxyvinyl ketones with 2-aminoacetophenone. 
combination of [HMIM][TsO] and TsOH improved the catalytic effect in the second attack for the formation of the final product. ${ }^{15}$

The mechanism proposed here results in the same regioisomer as that which is formed in the other two proposed mechanisms. ${ }^{7}$ The X-ray structure of the compound $3 \mathbf{c}$ (Figure 1) supports the mechanism suggested for this reaction.

\section{Conclusions}

In summary, the method proposed in this study allows the preparation of a set of novel 3-haloacylquinolines from 4-alkoxyvinyl ketones and 2-aminoacetophenone, exploring the reactivity of 4-alkoxyvinyl ketones, i.e., their electrophilic and nucleophilic sites. In addition, it was demonstrated the synergic effects of ionic liquids and microwave in the synthesis of quinolines, resulting in reactions performed in short times and providing good yields.

\section{Acknowledgements}

The authors thank the Conselho Nacional de Desenvolvimento Científico e Tecnológico (CNPq, Universal/ Proc. 485893/2007-0, Universal/Proc. 471519/2009-0 and MAPA/Proc. 578426/2008-0) and the Fundação de Amparo à Pesquisa do Estado do Rio Grande do Sul (FAPERGS, PRONEX/Proc. 10/0037-8) for financial support. Fellowships from CNPq (M. A. P. M., N. Z., H. G. B., D. N. M., M. R. B. M. and L. D. T. P.), CAPES (C. P. F., PRODOC-CAPES/Proc. 2684-32/2010, L.B.) and FAPERGS are also acknowledged.

\section{Supplementary Information}

Supplementary information (spectral data of compounds) is available free of charge at http://jbcs.sbq.org.br as PDF file.

\section{References}

1. Wiesner, J.; Ortmann, R.; Jomaa, H.; Schlitzer, M.; Angew. Chem., Int. Ed. 2003, 42, 5274.

2. Tumer, R. R.; Woodward, R. R.; The Alkaloids; R. H. F. Manske ed.; Academic Press: New York, 1953.

3. Stork, G.; Niu, D.; Fujimoto, A.; Koft, E. R.; Balkovec, J.; Tata, J. R.; Dake, G. R.; J. Am. Chem. Soc. 2001, 123, 3239.

4. Raheem, I.T.; Goodman, S. N.; Jacobsen, E. N.; J. Am. Chem. Soc. 2004, 126, 706.

5. Balasubramanian, M.; Keay, J. G.; Comprehensive Heterocyclic Chemistry II, Katritzky, A. R.; Rees C. W., eds.; Pergamon Press: New York, 1996.
6. Kouznetsov, V. V.; Méndez, L. Y. V.; Gómez, C. M. M.; Curr. Org. Chem. 2005, 9, 141.

7. Marco-Contelles, J.; Pérez-Mayoral, E.; Samadi, A.; Carreiras, M. C.; Soriano, E.; Chem. Rev. 2009, 109, 2652.

8. Ghassamipour, S.; Sardarian, A. R.; Tetrahedron Lett. 2009, 50, 514.

9. Atechian, S.; Nock, N.; Norcross, R. D.; Ratni, H.; Thomas, A. W.; Verron, J.; Masciadri, R.; Tetrahedron 2007, 63, 2811; Bose, D. S.; Idrees, M.; Jakka, N. M.; Rao, J. V.; J. Comb. Chem. 2010, 12, 100.

10. Sridharan, V.; Ribelles. P.; Ramos, M. T.; Menéndez, J. C.; J. Org. Chem. 2009, 74, 5715.

11. Hosseini-Sarvari, M.; Can. J. Chem. 2009, 87, 1122.

12. Barbero, M.; Bazzi, S.; Cadamuro, S.; Dughera, S.; Tetrahedron Lett. 2010, 51, 2342.

13. Martins, M. A. P.; Sinhorin, A. P.; Zimmermann, N. E. K.; Zanatta, N.; Bonacorso, H. G.; Bastos, G. P.; Synthesis 2001, 1959.

14. Martins, M. A. P.; Scapin, E.; Frizzo, C. P.; Rosa, F. A.; Bonacorso, H. G.; Zanatta, N.; J. Braz. Chem. Soc. 2009, 20, 205.

15. Moreira, D. N.; Frizzo, C. P.; Longhi, K.; Zanatta, N.; Bonacorso, H. G.; Martins, M. A. P.; Monatsh. Chem. 2008, 139, 1049.

16. Martins, M. A. P.; Moreira, D. N.; Frizzo, C. P.; Longhi, K.; Zanatta, N.; Bonacorso, H. G.; J. Braz. Chem. Soc. 2008, 19, 1361.

17. Buriol, L.; Frizzo, C. P.; Prola, L. D. T.; Moreira, D. N.; Marzari, M. R. B.; Scapin, E.; Zanatta, N.; Bonacorso, H. G.; Martins, M. A. P.; Catal. Lett. 2011, 141,1130.

18. Flores, A. F. C.; Zanatta, N.; Rosa, A.; Brondani, S.; Martins, M. A. P.; Tetrahedron Lett. 2002, 43, 5005.

19. Bonacorso, H. G.; Bittencourt, S. R. T.; Lourega, R. V.; Flores, A. F. C.; Zanatta, N.; Martins, M. A. P.; Synthesis 2000, 10, 1431.

20. Martins, M. A. P.; Cunico, W.; Pereira, C. M. P.; Sinhorin, A. P.; Flores, A. F. C.; Bonacorso, H. G.; Zanatta, N.; Curr. Org. Synth. 2004, 1, 391.

21. Bonacorso, H. G.; Moraes, T. S.; Zanatta, N.; Martins, M. A. P.; Flores, A. F. C.; Arkivoc 2008, 75.

22. Staderini, M.; Cabezas, N.; Bolognesi, M. L.; Menéndez J. C.; Synlett 2011, 2577.

23. Jia, C.-S.; Zhang, Z.; Tu, S.-J.; Wang, G.-W.; Org. Biomol. Chem. 2006, 4, 104.

24. Heravi, M. R. P.; Ultrason. Sonochem. 2009, 16, 361.

25. Stadler, A.; Kappe, C. O.; Eur. J. Org. Chem. 2001, 919.

26. Martins, M. A. P.; Frizzo, C. P.; Moreira, D. N.; Buriol, L.; Machado, P.; Chem. Rev. 2009, 109, 4140.

27. Martínez-Palou, R.; Mol. Diversity 2010, 14, 3.

28. Bruker; APEX2 (version 2.1), COSMO (version 1.56), BIS (version 2.0.1.9), SAINT (version 7.3A) and SADABS (version 2004/1) \& XPREP (version 2005/4), Bruker AXS Inc., Madison, Wisconsin, USA, 2006. 
29. Sheldrick, G. M.; SHELXS-97 and SHELXL-97, Program for Crystal Structure Refinement; University of Gottingen, Germany, 1997.

30. Coppens, P.; Leiserowitz, L.; Rabinovich, D.; Acta Cryst. 1965, 18, 1035.

31. Farrugia, L. J.; J. Appl. Crystallogr. 1997, 30, 565.
32. Zhao, G.V.; Jiang, T.; Gao, H. X.; Han, B. X.; Huang, J.; Sun, D. H.; Green Chem. 2004, 6, 75.

33. Martins, M. A. P; Frizzo, C. P.; Moreira, D. N.; Zanatta, N.; Bonacorso, H. G.; Chem. Rev. 2008, 108, 2015.

Submitted: March 19, 2012 Published online: August 28, 2012 